\title{
Preparation and Evaluation of Lipid Emulsion Containing I 3 Vitamins for Injection Without Anaphylactoid Reactions
}

\author{
Min-Quan Hui ${ }^{1,2, *}$ \\ Yan-Ni $\mathrm{Mi}^{1}{ }^{1} *$ \\ Yu-Fan $\mathrm{Ma}^{2}$ \\ Tao Chen ${ }^{2}$ \\ Yong-Xiao Cao (D) \\ 'Department of Pharmacology, Health \\ Science Center, X'an Jiaotong University, \\ Xi'an, People's Republic of China; ${ }^{2}$ Xi'an \\ Libang Pharmaceutical, Xi'an, People's \\ Republic of China \\ *These authors contributed equally to \\ this work
}

Correspondence: Yong-Xiao Cao Department of Pharmacology, Health Science Center, Xi'an Jiaotong University, 76 Yanta West Road, Xi'an, 71006I,

People's Republic of China

Tel +86-29-8265-5l 40

Email yxy@xjtu.edu.cn
Objective: Multivitamins containing Tween 80 can cause anaphylactoid reactions. The objective of this study was to develop a new lipid emulsion containing 13 fat- and watersoluble vitamins for injection (13V-LE) that were simultaneously dissolved in one bottle and to evaluate the stability of and anaphylactoid reactions to $13 \mathrm{~V}-\mathrm{LE}$.

Methods: Particle size, $\zeta$-potential, and polydispersity of 13V-LE were assayed with a Zetasizer Nano ZS. Entrapment efficiency of 13V-LE was determined with HPLC. Behavior, histamine, and blood pressure of beagle dogs were investigated by observation, fluorospectrophotometry, and sphygmomanometry.

Results: The 13V-LE with the smallest particles and highest entrapment efficiency with stable $\zeta$-potential was composed of soybean oil, glycerin $(2.25 \%$, w:v), egg lecithin $(1.2 \%, w: v)$, and purified water. There was no obvious change in characteristics of the $13 \mathrm{~V}$-LE samples in terms of appearance, size distribution, $\zeta$-potential, $\mathrm{pH}$ value, or concentration over 6 months. In anaphylactoid reactions tests, when being administered with the multivitamin Infuvite Adult containing Tween 80, six beagles showed grade IV symptoms $(P<0.01$ vs control), low blood pressure, and high plasma-histamine concentrations $(P<0.05$ or $P<0.01)$. However, there were no significant differences in behavior, blood pressure, or histamine concentration in the dogs before and after administration in the $13 \mathrm{~V}$-LE group.

Conclusion: The 13V-LE formulation is a suitable intravenous lipid emulsion without anaphylactoid reactions.

Keywords: anaphylactoid reaction, multivitamins, lipid emulsion, beagle dog

\section{Introduction}

Adverse drug reactions cause increased patient morbidity and mortality, are a considerable source of financial burden to the health-care system, and remain a huge challenge in modern health care. ${ }^{1}$ Adverse drug reactions occur in approximately $17 \%$ of patients. $^{2,3}$ Hypersensitivity reactions comprise approximately a third of adverse drug reactions. Anaphylactoid reactions represent $>60 \%$ of hypersensitivity reactions. ${ }^{4}$ Avoiding adverse drug reactions, especially anaphylactoid reactions, is essential from both an economic and ethical standpoint.

Nutrition is the source of healthy growth and organism activity, and indispensable for the recovery of patients. The prevalence of malnutrition in patients can be as high as $50 \% .^{5-8}$ Malnutrition has become an independent risk factor of mortality, morbidity, and hospitalization in patients. ${ }^{9-14}$ Multivitamins are conducive to the 
ingestion of essential vitamins to maintain the body's resistance and repair functions. Multivitamins are the most common supplement, and their use is increasing. ${ }^{15}$ Thirteen vitamins needed by the human body are mainly used in multivitamin preparations for parenteral nutrition support. ${ }^{16}$

The multivitamin Infuvite Adult is an injection containing 13 vitamins that has been widely used for years. The product comprises two bottles. Bottle 1 contains vitamins A, D, E, K, $\mathrm{C}, \mathrm{B}_{1}, \mathrm{~B}_{2}, \mathrm{~B}_{6}$, nicotinamide, and dexpanthenol. Tween 80 $(1.4 \%)$ is used to solubilize the fat-soluble vitamins $\mathrm{A}, \mathrm{D}, \mathrm{E}$, and $\mathrm{K}$, in bottle 1 . Bottle 2 contains vitamin $\mathrm{B}_{12}$, biotin, folic acid, using $30 \%$ propylene glycol as solvent. The two bottles are mixed before clinical injection. However, a problem occurs with the use of Tween 80 . There is increasing evidence that it can cause anaphylactoid reactions. ${ }^{17-19}$ Not surprisingly, multivitamins can produce severe and fatal anaphylactoid reactions. ${ }^{20-23}$ Tween 80 is not suitable as a solubilizing agent for intravenous preparations. In addition to Tween 80 induced anaphylactoid reactions, there are some difficulties in the study of multivitamin preparation. Fat-soluble vitamins are insoluble in water. It is difficult to dissolve fat- and watersoluble vitamins in the same system.

To solve these problems, a new lipid emulsion containing 13 fat- and water-soluble vitamins in one bottle (13V-LE) was developed in this study. Intravenous lipid emulsions were used to supply essential fatty-acids to patients with intestinal failure who needed parenteral nutrition in the US in the $1970 \mathrm{~s} .{ }^{24}$ Over the last 50 years, new lipid emulsions have been continuously produced with the goal of improving security and efficacy and realizing physiologically optimal formulations. ${ }^{24}$ In the present day, lipid emulsions have become a tool for systemic delivery of poorly soluble and cytotoxic drugs. ${ }^{25,26} 13 \mathrm{~V}$-LE combines water-soluble and fat-soluble vitamins without Tween 80 and forms a cosoluble single freeze-dried compound, which could improve vitamins stability and avert hypersensitivity. The objective of this study was to evaluate the stability and the anaphylactoid reactions of 13V-LE.

\section{Methods}

\section{Materials}

Vitamins were purchased from Disiman Vitamin (Shanghai, China). Poloxamer 188 (Pluronic F68) was purchased from Shanghai Qingyuanxing Chemical Technology (Shanghai, China). Glycerol, oleate, soybean oil, and egg lecithin (PC 98\%) was supplied by Xi'an
Libang Pharmaceutical (Shaanxi, China) and $\alpha$ Tocopherol purchased from Sigma-Aldrich (MO, USA).

\section{Preparation}

Formulation and optimized composition of 13V-LE were begun with filtration sterilization and ultrasonic treatment. Briefly, in the case of 13V-LE, fat-soluble vitamins and soybean oil were considered as oil phase. Egg lecithin and oleate acid were chosen as emulsifier. Water-soluble vitamins, glycerin, and purified water were considered as a water phase.

The new multivitamin 13V-LE contains nine water-soluble vitamins $\left(\mathrm{B}_{1}, \mathrm{~B}_{2}, \mathrm{~B}_{6}, \mathrm{~B}_{12}, \mathrm{C}\right.$, nicotinamide, dexpanthenol, biotin, and folic acid) and four kinds of liposoluble vitamins (including vitamins $\mathrm{A}, \mathrm{D}_{3}, \mathrm{E}$, and $\mathrm{K}_{1}$ ). These are shown in Table 1. In order to solve the problem of the cosolubility of water-soluble and liposoluble vitamins in the same system, 16 emulsifier formulations were designed, as presented in Table 2. Various proportions of lecithin, F68, oleate, and Tween 80 were used as emulsifiers for the preparation of 13V-LE. Soybean oil was considered as a solvent of the oil phase. Glycerin (2.25\%,w:v) and purified water were considered as a solvent of the water phase in the preparation of the different formulations. Based on physical appearance, particle size, $\zeta$ potential, and entrapment efficiency (EE), an optimized formulation of emulsifiers was chosen.

To prepare 13V-LE, egg lecithin was dissolved into dehydrated alcohol and agitated until dissolved with the addition of fat-soluble vitamins. Then, soybean oil was added in the dissolved solution and heated at $70^{\circ} \mathrm{C}$ until the mixture had become a clear and stable oil phase containing emulsifier. Glycerin and oleate acid were dissolved in water and heated at $70^{\circ} \mathrm{C}$ to form a water phase. After that, the water-phase

Table I Composition of I 3V-LE

\begin{tabular}{|l|c|}
\hline Components & Quantity \\
\hline Vitamin $A$ & $3,300 \mathrm{IU}$ \\
Vitamin $\mathrm{D}_{3}$ & $200 \mathrm{IU}$ \\
Vitamin $\mathrm{E}$ & $10 \mathrm{IU}$ \\
Vitamin $\mathrm{K}_{1}$ & $0.15 \mathrm{mg}$ \\
Vitamin $\mathrm{B}_{1}$ & $6 \mathrm{mg}$ \\
Vitamin $\mathrm{B}_{2}$ & $3.6 \mathrm{mg}$ \\
Vitamin $\mathrm{B}_{6}$ & $6 \mathrm{mg}$ \\
Vitamin $\mathrm{B}_{12}$ & $0.005 \mathrm{mg}$ \\
Vitamin $C$ & $200 \mathrm{mg}$ \\
Biotin & $0.06 \mathrm{mg}$ \\
Niacinamide & $40 \mathrm{mg}$ \\
Dexpanthenol & $15 \mathrm{mg}$ \\
Folic acid & $0.6 \mathrm{mg}$ \\
\hline
\end{tabular}


Table 2 Emulsifiers for I3V-LE (w:v, \%)

\begin{tabular}{|l|c|c|c|c|}
\hline Formulations & Lecithin & F68 & Oleate & Tween 80 \\
\hline FI & 0.6 & 0 & 0 & 0 \\
F2 & 0.6 & 0.2 & 0.04 & 0.2 \\
F3 & 0.6 & 0.4 & 0.06 & 0 \\
F4 & 0.6 & 0.6 & 0.02 & 0.2 \\
F5 & 1.2 & 0 & 0 & 0 \\
F6 & 1.2 & 0 & 0.06 & 0.2 \\
F7 & 1.2 & 0.6 & 0.04 & 0 \\
F8 & 1.2 & 0.4 & 0.02 & 0 \\
F9 & 2.0 & 0.4 & 0.04 & 0.2 \\
FI0 & 2.0 & 0.6 & 0 & 0 \\
FII & 2.0 & 0 & 0.02 & 0.2 \\
FI2 & 2.0 & 0.2 & 0.06 & 0 \\
FI3 & 3.0 & 0.6 & 0.06 & 0.2 \\
FI4 & 3.0 & 0.4 & 0.02 & 0 \\
FI5 & 3.0 & 0.2 & 0 & 0.2 \\
FI6 & 3.0 & 0 & 0.04 & 0 \\
\hline
\end{tabular}

solution was added slowly to the oil-phase solution containing the emulsifier. The coarse emulsion was prepared by high-speed shearing for 15 minutes at $70^{\circ} \mathrm{C}$ under the protection of nitrogen. The coarse emulsion was cooled to room temperature and adjusted to $\mathrm{pH} 5-7$ with $\mathrm{NaOH}$. The final emulsion was prepared with high-pressure homogenization (Niro Soavi NS1001L) at 1,000 bar for eight cycles at $40^{\circ} \mathrm{C}$. After homogenization, the water-soluble vitamins were added to form 13V-LE, then freeze-dried after sterilization through a $0.22 \mu \mathrm{m}$ bacteria-retentive filter.

\section{Characterization of Formulations}

Particle size, polydispersity, and $\zeta$-potential of the $13 \mathrm{~V}$ LE were assayed with a Zetasizer Nano ZS (Malvern Instruments). The samples of 13V-LE were redissolved in $5 \mathrm{~mL}$ water, then diluted to $1: 1,000$ with water before measurement. The $\mathrm{pH}$ value of the $13 \mathrm{~V}-\mathrm{LE}$ was tested with a $\mathrm{pH}$ meter (PP-50 Professional Meter; Sartorius).

\section{Entrapment Efficiency}

The EE of the emulsions was assayed by vitamin concentration in the dispersion phase. $13 \mathrm{~V}-\mathrm{LE}$ was centrifuged at $50,000 \mathrm{rpm}$ for 1.5 hours at $4^{\circ} \mathrm{C}$ by ultracentrifugation (OPTIMA L-100XP; Beckman Coulter), then collected in the water phase. Vitamin concentrations in the water phase were measured with HPLC. EE was calculated:

$$
E E(\%)=\frac{C_{\text {total }} V_{\text {total }}-C_{\text {water }} V_{\text {water }}}{C_{\text {total }} V_{\text {total }}} \times 100
$$

where $\mathrm{C}_{\text {total }}$ is the concentration of vitamin in the emulsion, $\mathrm{V}_{\text {total }}$ the volume of the emulsion, $\mathrm{C}_{\mathrm{water}}$ the concentration of vitamin in the water phase after ultracentrifugation, and $V_{\text {water }}$ the volume of water phase collected after ultracentrifugation.

Vitamin A was the most abundant and unstable in the oil phase among the vitamins of 13V-LE, so the stability of the formulation was determined by examining the encapsulation rate of vitamin A. The concentration of fat-soluble vitamin A was measured with HPLC using a Waters 2996 UV detector. The column was an Agilent XDB-C ${ }_{18}(4.6 \times 150 \mathrm{~mm}, 5 \mu \mathrm{m})$, and the mobile phase was a mixture (methanol : isopropanol 95:5 v:v). The wavelength was $326 \mathrm{~nm}$ and the injection volume $10 \mu \mathrm{L}$. The flow rate of the mobile phase was $1.2 \mathrm{~mL} / \mathrm{min}$. The column temperature was $25^{\circ} \mathrm{C}$. All measurements were repeated in triplicate.

\section{Stability}

13V-LE was stored at $40 \pm 2^{\circ} \mathrm{C}$ and at room temperature for 6 months. After that, the physical and chemical stability of these samples were evaluated with assays of appearance,

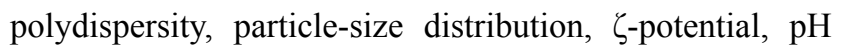
value, and drug remaining. All measurements were repeated three times. For appearance evaluation, if a lipid emulsion is stratified, aggregated, flocculated, produces small oil droplets on the surface, or shows other anomalous changes, it can be defined as "bad". If a lipid emulsion is homogeneous and shows no anomalous changes, it can be defined as "good".

\section{Compatibility}

Compatibility of the 13 vitamins with pharmaceutical excipients and that of 13V-LE with different infusion solutions were investigated. Vitamins were mixed with different pharmaceutical excipients, as shown in Supplementary Table 1 . These mixtures were exposed to high temperature $\left(60^{\circ} \mathrm{C}\right)$, damp $(90 \% \pm 5 \%)$, light of 4,500 $\pm 500 \mathrm{~lx}$ for 10 days. The content of vitamins and related substances were tested with HPLC. To test compatibility with different infusion solutions, samples of 13V-LE were redissolved in $5 \mathrm{~mL}$ water for injection, then diluted to $500 \mathrm{~mL}$ with $0.9 \%$ sodium chloride solution, $5 \%$ glucose injection, and fatemulsion injection. The osmotic pressure of these mixtures was measured with an Osmomat-3000D (Gonotec). 


\section{Anaphylactoid Reaction Tests}

Animals and Treatments

Six beagle dogs (three male, three female) weighing 8-12 kg were purchased from Xi'an Dilepu Biology Resources (Shaanxi, China). They were housed in separate cages and allowed access to food and water ad libitum in an environment at room temperature with $40 \%-70 \%$ humidity, and a day-night cycle of 12-12 hours. The dogs were handled in accordance with the criteria outlined in the Guide for Care and Use of Laboratory Animals. All experimental protocols were approved by the Animal Ethics Committee at Xi'an Jiaotong University (2017-0045).

13V-LE and Infuvite Adult are compound vitamin injections. The content of each vitamin in the injections is different and the units of measurement inconsistent. For the convenience of research and calculation, vitamin $\mathrm{C}$ was used as a marker of 13V-LE and Infuvite Adult to calculate the dose. The dose of vitamin C in 13V-LE and Infuvite Adult for an adult is $200 \mathrm{mg}$ /day. When human body weight is set at $70 \mathrm{~kg}$, the dose of vitamin C is $2.9 \mathrm{mg} / \mathrm{kg}$. The dose-converse factor of dog:person is 1.85. Therefore, the equivalent dose of vitamin $\mathrm{C}$ for a dog is $5.3 \mathrm{mg} / \mathrm{kg}$. In this study, $6 \mathrm{mg} / \mathrm{kg}$ vitamin $\mathrm{C}$ was selected as the dose for the dogs.

There were three groups in the anaphylactoid reaction tests: control (normal saline), 13V-LE, and Infuvite Adult. On the first day of the dosing regimen, all six beagles received intravenous saline injections as the control group. Then, all dogs were divided into two groups of three animals each. Two groups of dogs were cross-injected with Infuvite Adult and 13V-LE on the second and fourth days. On the second day, dogs 1-3 were intravenously injected with Infuvite Adult and dogs 4-6 intravenously injected 13V-LE. On the fourth day, dogs 1-3 were intravenously injected with 13V-LE dogs 4-6 dogs intravenously injected with Infuvite Adult (Table 3). Blood samples were collected in tubes with heparin before and 10 minutes after administration. Samples were centrifuged for 10 minutes, then plasma collected and stored at $-20^{\circ} \mathrm{C}$ until analysis.

Table 3 Modes of administration in anaphylactoid reaction tests

\begin{tabular}{|l|l|c|c|}
\hline \multirow{2}{*}{ Dogs } & \multicolumn{3}{|c|}{ Time of administration } \\
\cline { 2 - 4 } & Day I & Day 2 & Day 4 \\
\hline I-3 & Normal saline & Infuvite Adult & I3V-LE \\
$4-6$ & Normal saline & I3V-LE & Infuvite Adult \\
\hline
\end{tabular}

\section{Behavioral Observation}

Before and after administration, dogs' eyes, mouth, neck, abdomen, limbs, skin, behavior, gait, and body coordination were observed for 30 minutes for anaphylactoid reactions. Levels of reaction were assessed using the criterion in Supplementary Table 2.

\section{Plasma-Histamine Concentration}

Concentrations of plasma histamine were measured with fluorescence spectroscopy. Ethyl alcohol $(300 \mu \mathrm{L})$ was added to plasma samples of $100 \mu \mathrm{L}$ for deproteinization. The supernatant was tested after vortex mixing and centrifugation at $10,000 \mathrm{~g}$. Sample supernatants $(100 \mu \mathrm{L})$ were added to $0.5 \mathrm{M} \mathrm{NaOH}$ solution $(40 \mu \mathrm{L})$ and $2.5 \mu \mathrm{g} / \mathrm{mL} o$-phthalaldehyde $(20 \mu \mathrm{L})$ and incubated at $37^{\circ} \mathrm{C}$ for 30 minutes. Subsequently, $10 \mu \mathrm{L} 3 \mathrm{M} \mathrm{HCl}$ solution was added to terminate the reaction. The excitation wavelength was $365 \mathrm{~nm}$ and the emission wavelength $465 \mathrm{~nm}$. The fluorescence intensity of samples was detected with a fluorescence plate reader, and the standard curve was drawn, and then histamine concentrations of samples were calculated.

\section{Blood-Pressure Detection}

Blood pressure was measured with an OMRON HEM-8611 at $0,10,20$, and 30 minutes after administration of drugs. Dogs were put in the decubitus position without anesthesia and the blood-pressure monitor put on the arm. Measurements were repeated in triplicate at each time point.

\section{Statistical Analysis}

SPSS 11.5 was used for statistical analyses. All data are shown as means \pm SE. $P<0.05$ was considered statistically significant. ANOVA with least significant difference was used to analyze quantitative data in multiple groups, including blood pressure at different time points. Student's $t$-test was used to analyze quantitative data between two groups, such as concentrations of histamine. The rank-sum test was used to analyze ordinal data, such as grades of behavior, in the anaphylactoid-reaction tests.

\section{Results and Discussion Composition and Stability of I3V-LE HPLC}

Representative chromatograms were shown in Supplementary Figure 1. The peak of vitamin A was eluted within about 33 minutes under the analytical conditions described. The reproducibility of the detection was studied with repeated injections in triplicate samples containing 
vitamin A at three concentrations $(2,3$, and $4 \mu \mathrm{g} / \mathrm{mL})$. Relative standard deviation was $<0.3 \%$. The relative recovery of vitamin A at 2, 3, and $4 \mu \mathrm{g} / \mathrm{mL}$ was $101.8 \% \pm 0.0 \%$, $102.3 \% \pm 0.0 \%$, and $103.0 \% \pm 0.0 \%$, respectively $(n=3)$. The standard curve of vitamin A concentration was obtained: $y=3.401 x+73.986, R^{2}=0.9994$.

\section{Composition of I3V-LE}

In this study, a new formulation of intravenous lipid emulsions was developed to solve the problem of cosolvability of water-soluble vitamins $\left(\mathrm{B}_{1}, \mathrm{~B}_{2}, \mathrm{~B}_{6}, \mathrm{~B}_{12}, \mathrm{C}\right.$, nicotinamide, dexpanthenol, biotin, and folic acid) and liposoluble vitamins $\left(\mathrm{A}, \mathrm{D}_{3}, \mathrm{E}\right.$, and $\left.\mathrm{K}_{1}\right)$ in the same system. The appearance, $\zeta$ potential, particle-size distribution, and EE of $13 \mathrm{~V}$-LE in the different emulsifiers (lecithin, F68, oleate, and Tween 80) were assessed to select the optimal formulation of $13 \mathrm{~V}$-LE. In the emulsified state, 13V-LE was in an oil-in-water state, and the four liposoluble vitamins (A, D3, E, and $\mathrm{K}_{1}$ ) were encased in oil in the lipid emulsion. Commonly, only the EE of encased vitamins needs to be evaluated. Vitamin A was the most abundant and unstable vitamin in the oil phase in $13 \mathrm{~V}$ LE. Therefore, it was was chosen as a representative to evaluate the stability of the formulation by examining its EE. As shown in Table 4, F1, F4, F6, F9, F10, F13, and F14 were inferior formulations with poor appearance, such as oil drops, stratification, or flocculation. 13V-LE particle size increased with increasing lecithin content. When emulsifiers contained $0.6 \%$ lecithin, F68, oleate, and Tween 80 in F2 and
F3, this contributed to emulsion formation, but with low EE. Particles of F7, F8, F11, F12, F13 and F14 containing F68 or oleate were larger than those of F5 containing lecithin. When an emulsifier contained only $1.2 \%$ lecithin, the emulsion had the smallest particles and highest EE of vitamin A with stable $\zeta$-potential (F5). Therefore, egg lecithin 1.2\% (w:v) was chosen as an emulsifier.

Before freeze-drying, 13V-LE is an oil-in-water lipid emulsion. The new multivitamin 13V-LE cont ains 3,300 IU (990 $\mu \mathrm{g})$ vitamin A, $200 \mathrm{IU}$ vitamin $\mathrm{D}_{3}, 10$ IU (9.1 mg) vitamin E, $0.15 \mathrm{mg}$ vitamin $\mathrm{K}_{1}, 200 \mathrm{mg}$ vitamin $\mathrm{C}$, $6 \mathrm{mg}$ vitamin $\mathrm{B}_{1}, 3.6 \mathrm{mg}$ vitamin $\mathrm{B}_{2}, 6 \mathrm{mg}$ vitamin $\mathrm{B}_{6}$, $40 \mathrm{mg}$ nicotinamide, $15 \mathrm{mg}$ dexpanthenol, $0.005 \mathrm{mg}$ vitamin $\mathrm{B}_{12}, 0.06 \mathrm{mg}$ biotin, $0.6 \mathrm{mg}$ folic acid, soybean oil, egg lecithin $(1.2 \%, \mathrm{w}: \mathrm{v})$, glycerin $(2.25 \%, \mathrm{w}: \mathrm{v}), \mathrm{NaOH}$, and water. Fat-soluble vitamins and soybean oil were considered as oil phase, egg lecithin was chosen as an emulsifier, and water-soluble vitamins, glycerin, and water were considered as water phase in $13 \mathrm{~V}$-LE.

\section{Characterization of Lipid Emulsions}

The 13V-LE dispersion, composed of soybean oil, glycerin, egg lecithin, 13 vitamins, and purified water, was analyzed in terms of size and polydispersity. As shown in Figure $1 \mathrm{~A}$, the mean diameter of $13 \mathrm{~V}-\mathrm{LE}$ was $<200 \mathrm{~nm}$, which is suitable for parenteral administration. Polydispersity is a dimensionless parameter of size distribution for broadness. The lower the polydispersity, the

Table 4 Effects of different emulsions on characterization of I 3V-LE

\begin{tabular}{|c|c|c|c|c|}
\hline \multirow[t]{2}{*}{ Formulations } & \multicolumn{4}{|c|}{ Characterization of I3V-LE } \\
\hline & Physical appearance & Particle size $(\mathrm{nm})$ & $\zeta$-potential (mV) & Entrapment efficiency of vitamin A (\%) \\
\hline $\mathrm{FI}$ & Oil drops & - & - & - \\
\hline F2 & Good & $152.4 \pm 8.7$ & $-20.2 \pm 1.5$ & $70.4 \pm 3.1$ \\
\hline F3 & Good & $176.3 \pm 11.7$ & $-26.3 \pm 1.9$ & $85.5 \pm 2.0$ \\
\hline $\mathrm{F} 4$ & Stratification & - & - & - \\
\hline F5 & Good & $|2| . \mid \pm 6.0$ & $-27.7 \pm 2.1$ & $99.7 \pm 0.3$ \\
\hline F6 & Oil drops & - & - & - \\
\hline F7 & Good & $205.1 \pm 3.2$ & $-29.6 \pm 3.4$ & $94.9 \pm 1.4$ \\
\hline F8 & Good & $186.8 \pm 5.5$ & $-24.0 \pm 2.0$ & $98.2 \pm 0.4$ \\
\hline F9 & Flocculation & - & - & - \\
\hline FIO & Oil drops & - & - & - \\
\hline FII & Good & $194.1 \pm 5.0$ & $-25.4 \pm 2.0$ & $95.3 \pm 1.2$ \\
\hline $\mathrm{FI} 2$ & Good & $215.8 \pm 9.0$ & $-30.7 \pm 1.6$ & $92.4 \pm 3.2$ \\
\hline $\mathrm{FI} 3$ & Oil drops & - & - & - \\
\hline $\mathrm{FI} 4$ & Oil drops & - & - & - \\
\hline FI5 & Good & $217.3 \pm 3.8$ & $-25.8 \pm 1.4$ & $94.6 \pm 2.1$ \\
\hline FI6 & Good & $226.8 \pm 6.6$ & $-29.5 \pm 1.9$ & $93.8 \pm 2.5$ \\
\hline
\end{tabular}

Note: $n=3$. 


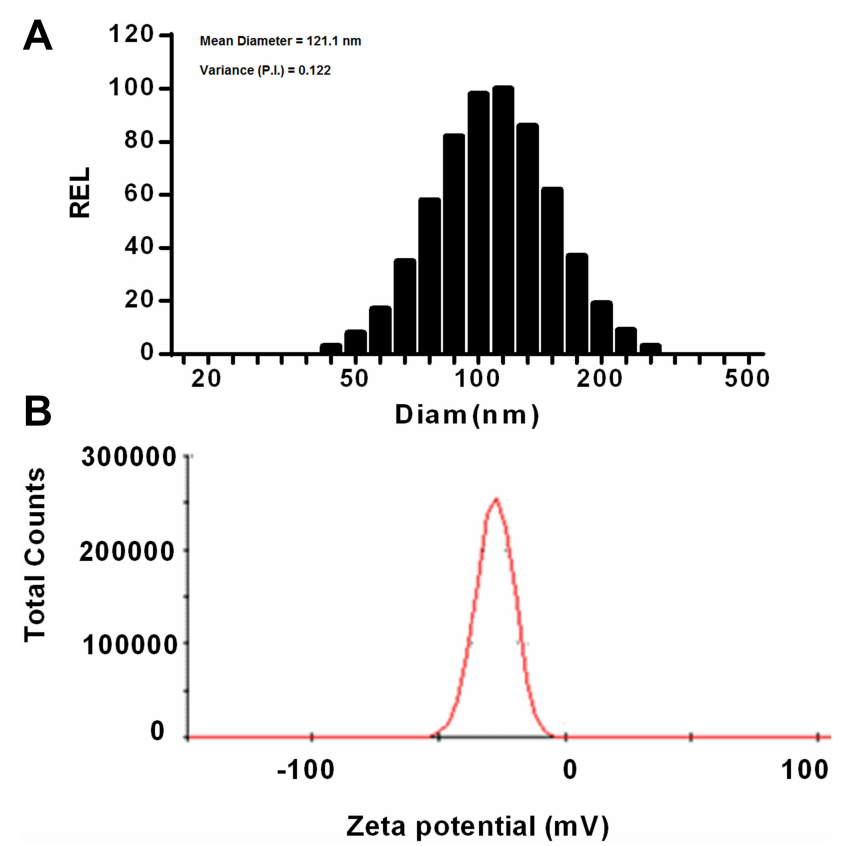

Figure I Particle-size and the $\zeta$-potential distribution of I3V. (A) Particle-size distribution; (B) $\zeta$-potential distribution. I3V-LE samples were diluted I:I,000 with purified water. Particle size and polydispersity were measured with a Zetasizer Nano ZS. Measurements were performed in triplicate.

Abbreviation: PI, polydispersity index.

narrower the distribution of lipid emulsion. The mean polydispersity of $13 \mathrm{~V}-\mathrm{LE}$ was $<0.2$, showing that $13 \mathrm{~V}$ LE had proper delivery.

$\zeta$-potential is a crucial parameter of emulsion stability. It determines the size of electrostatic repulsion among particles, which affects the aggregation of particles and the stability of a lipid emulsion. Generally, $\zeta$-potential ranges from $-20 \mathrm{mV}$ to $-45 \mathrm{mV}$, while that of $13 \mathrm{~V}$-LE was $-27.7 \pm 2.1 \mathrm{mV}$, suggesting that the emulsions were stable (Figure 1B).

\section{Stability of I3V-LE}

$13 \mathrm{~V}$-LE was stored at $25^{\circ} \mathrm{C}$ and $40^{\circ} \mathrm{C}$ for 6 months, then its stability was studied by monitoring size and polydispersity. Table 5 shows that the appearance, particle-size distribution, $\mathrm{pH}$ value, $\zeta$-potential, and vitamin A content of the $13 \mathrm{~V}$-LE samples underwent no significant change in 6 months, suggesting that $13 \mathrm{~V}-\mathrm{LE}$ had favorable stability. Severe test, accelerated, and long-term storage tests also showed that 13V-LE had favorable stability (Supplementary Table 3-5).

Multivitamins/minerals refers to any supplement containing three or more vitamins or minerals, but no herbs, hormones, or drugs, with each component at a dose less than the tolerable upper level determined by the US Food and Nutrition Board, ie, the maximum daily intake likely to pose
Table 5 Physical stability of I 3V-LE during 6 months $(n=3)$

\begin{tabular}{|l|c|c|c|}
\hline $\begin{array}{l}\text { Characterizations of } \\
\text { I3V-LE }\end{array}$ & O Month & $\begin{array}{c}\mathbf{6} \text { Months } \\
\text { at } \mathbf{4 0} \mathbf{0}^{\circ}\end{array}$ & $\begin{array}{c}\mathbf{6} \text { Months } \\
\text { at } 25^{\circ} \mathbf{C}\end{array}$ \\
\hline Physical appearance & Good & Good & Good \\
\hline $\mathrm{pH}$ value & $6.35 \pm 0.13$ & $6.17 \pm 0.18$ & $6.26 \pm 0.2$ \\
\hline $\begin{array}{l}\text { Average particle size } \\
(\mathrm{nm})\end{array}$ & $121.1 \pm 6.0$ & $132.5 \pm 11.7$ & $125.4 \pm 9.0$ \\
\hline $\begin{array}{l}\text { Average } \zeta \text {-potential } \\
(\mathrm{mV})\end{array}$ & $-27.7 \pm 2.1$ & $-28.1 \pm 3.1$ & $-26.2 \pm 3.0$ \\
\hline $\begin{array}{l}\text { Content of vitamin } \\
\text { A (\%) }\end{array}$ & $99.7 \pm 0.2$ & $96.0 \pm 1.9$ & $98.1 \pm 1.4$ \\
\hline
\end{tabular}

no risk of adverse health effects. ${ }^{27}$ The content of the vitamins in $13 \mathrm{~V}-\mathrm{LE}$ is the same as that in Infuvite Adult. The differences between 13V-LE and Infuvite Adult are their form and pharmaceutic adjuvants. Tween 80 is used to solubilize the fat-soluble vitamins in Infuvite Adult. In order to avoid Tween 80-induced anaphylactoid reactions, a lipid emulsion was chosen to be the drug-carrier system for 13V-LE. Lipid emulsions have been a significant component of parenteral nutrition and play a crucial role in supplying calories, providing necessary fatty acids that cannot be endogenously synthesized, and more importantly improving safety and efficacy and achieving physiologically optimal formulations. ${ }^{24}$ Soybean oil, which has high phytosterol content, was the triglyceride source of the first lipid emulsion manufactured and successfully administered intravenouly. ${ }^{28}$ Egg lecithin, a natural phospholipid, is used in oral, dermal, and parenteral products, including oil-inwater emulsions as an emulsifier. ${ }^{29}$ Soybean oil, egg lecithin, and glycerin formed a stable and homogeneous drug-carrier system for $13 \mathrm{~V}$-LE, with high $\zeta$-potential and low polydispersity. Many vitamins, such as vitamin $\mathrm{C}$, are sensitive and easily lost during handling, processing, and storage. ${ }^{30}$ Loss of vitamin $\mathrm{C}$ during storage is lower in freeze-dried powder than vacuum, tunnel-dried, or fresh powder. ${ }^{31,32}$ Cernevit is also a cosoluble single freeze-dried compound containing nine water-soluble vitamins and three liposoluble vitamins without vitamin K. Freeze-dried technology is conducive to the stability of vitamins. Our testing suggested that $13 \mathrm{~V}-\mathrm{LE}$ had good stability.

\section{Compatibility of I3V-LE}

The compatibility of vitamins with the pharmaceutical excipients soybean oil, egg lecithin, glycerin, F68, Tween 80, and oleate was investigated. The content of each vitamin and 
the related substances did not change significantly and was within the range of standard requirements, suggesting that the vitamins had good compatibility with these excipients (Supplementary Table 6). The 13V-LE was mixed with $0.9 \%$ sodium chloride solution, 5\% glucose injection, and fat-emulsion injection. None of these mixtures showed anomalous changes in appearance, such as stratification, aggregation, and flocculation. The osmotic pressure of these mixtures were $290.3 \pm 0.9 \mathrm{Osm} / \mathrm{kg}, 292.7 \pm 0.9 \mathrm{Osm} /$ $\mathrm{kg}$, and $301.7 \pm 1.8 \mathrm{Osm} / \mathrm{kg}$, respectively (Table 6). The osmotic pressure of human blood is $285-310 \mathrm{Osm} / \mathrm{kg}$. The range of osmotic pressure required for intravenous preparations should be the same as the osmotic pressure of blood in the body. The results of osmotic pressure suggested that $13 \mathrm{~V}-\mathrm{LE}$ had good compatibility with different infusion solutions. The drug-carrier system of 13V-LE consisting of soybean oil, egg lecithin, and glycerin is similar to that of propofol, which is an intravenous anesthetic and Vitalipid, which is a fat-soluble injection containing vitamins A, D, E, and $\mathrm{K}_{1} \cdot{ }^{33}$ These products have good stability and compatibility with parenteral nutrition admixtures.

\section{Anaphylactoid Reactions}

\section{Alterations in Behavior}

The behavior of the dogs was observed in anaphylactoid reaction tests. The six beagles of the saline group did not show any abnormal behavior within 30 minutes after administration (Table 7 and Figure 2). In the 13V-LE group, there was no abnormal behavior after intravenous infusion of $13 \mathrm{~V}$ LE. Within 30 minutes after intravenous administration of Infuvite Adult, the six dogs displayed grade IV symptoms, such as nose and head scratching and ear flicking ( $>3$ minutes), multiple skin and mucous rubeosis, skin rash, tachypnea, instability of gait, diarrhea, pawing the ground, rubbing the ground, rollingover, somnolence, hypodynamia, and wheezing. Figure 2 show the influence of 13V-LE on the skin of the dogs. There was multiple skin and mucous rubeosis and skin rash in dogs who had been administered Infuvite Adult. Anaphylactoid reactions were grade IV with a mean

Table 6 Osmotic pressure of I3V-LE mixed with different infusion solutions $(n=3)$

\begin{tabular}{|l|c|c|}
\hline & $\begin{array}{c}\text { Compatibility } \\
\text { volume }(\mathbf{m L})\end{array}$ & $\begin{array}{c}\text { Osmotic pressure } \\
\text { (Osm/kg) }\end{array}$ \\
\hline Normal saline & 500 & $290.3 \pm 0.9$ \\
$5 \%$ Glucose & 500 & $292.7 \pm 0.9$ \\
Fat emulsion & 500 & $301.7 \pm 1.8$ \\
\hline
\end{tabular}

Table 7 Anaphylactoid reaction tests

\begin{tabular}{|l|c|c|c|c|c|c|c|c|c|}
\hline \multirow{2}{*}{} & \multicolumn{7}{|c|}{ Dogs (n) } & \multirow{2}{*}{ Score } & \multirow{2}{*}{ Grade } \\
\cline { 2 - 7 } & 0 & I & II & III & IV & V & VI & & \\
\hline Control & 6 & 0 & 0 & 0 & 0 & 0 & 0 & 0 & 0 \\
I3V-LE & 6 & 0 & 0 & 0 & 0 & 0 & 0 & 0 & 0 \\
Infuvite & 0 & 0 & 0 & 0 & 6 & 0 & 0 & 25.5 & $4 \pm 0 * *$ \\
Adult & & & & & & & & $\pm 3 . I^{* *}$ & \\
\hline
\end{tabular}

Notes: Behavior of beagles observed for 30 minutes after the intravenous administration of drugs. Values are means $\pm S E, n=6$. $* * P<0.01$ vs control.

score of 25.5 \pm 3.1 , which was obviously higher than the control and 13V-LE groups $(P<0.01$, Table 7). These results indicated that $13 \mathrm{~V}$-LE did not induce any anaphylactoid reaction, but Infuvite Adult did induce anaphylactoid reactions triggered by Tween 80 .

\section{Alterations in Blood Pressure}

Before administration of Infuvite Adult, systolic and diastolic blood pressure of the dogs were $122 \pm 3 \mathrm{mmHg}$ and $69 \pm 3$ $\mathrm{mmHg}$, respectively. Systolic pressure decreased to $93 \pm 4$ $\mathrm{mmHg}$ at 10 minutes after drug administration, which was significantly lower than systolic pressure before administration $(P<0.01)$. Diastolic pressure was $58 \pm 5 \mathrm{mmHg}$, and there was a declining trend. Systolic pressure at 20 and 30 minutes after administration were $86 \pm 7 \mathrm{mmHg}$ and $81 \pm 8 \mathrm{mmHg}$, respectively, which significantly decreased $(P<0.01)$. Diastolic pressure was also lower than before administration $(P<0.01)$. Obviously, Infuvite Adult caused a decline of blood pressure.

There was no obvious alteration in blood pressure within 30 minutes after the intravenous administration of $13 \mathrm{~V}-\mathrm{LE}$. In the $13 \mathrm{~V}$-LE group, systolic and diastolic pressure were $119 \pm 2 \mathrm{mmHg}$ and $68 \pm 3 \mathrm{mmHg}$, respectively, before administration. Systolic pressure was $117 \pm 2$ $\mathrm{mmHg}, 112 \pm 4 \mathrm{mmHg}$, and $112 \pm 3 \mathrm{mmHg}$ at 10,20 , and 30 minutes, respectively, after intravenous administration of $13 \mathrm{~V}$-LE. Diastolic pressure was $71 \pm 2 \mathrm{mmHg}, 68 \pm 4$ $\mathrm{mmHg}$, and $64 \pm 4 \mathrm{mmHg}$, respectively. Systolic and diastolic pressure did not show significant differences when compared with before administration (Figure 3). These results further demonstrated that $13 \mathrm{~V}$-LE had no influence on blood pressure, but Infuvite Adult did.

\section{Alterations in Plasma-Histamine Concentration}

In the Infuvite Adult group, plasma-histamine concentration increased from $3.1 \pm 0.5 \mu \mathrm{g} / \mathrm{mL}$ to $5.7 \pm 0.9 \mu \mathrm{g} / \mathrm{mL}$ after administration, an increase of $45.6 \%(P<0.05)$. In the $13 \mathrm{~V}$ LE group, there was no significant difference in plasma histamine concentration between before and after 


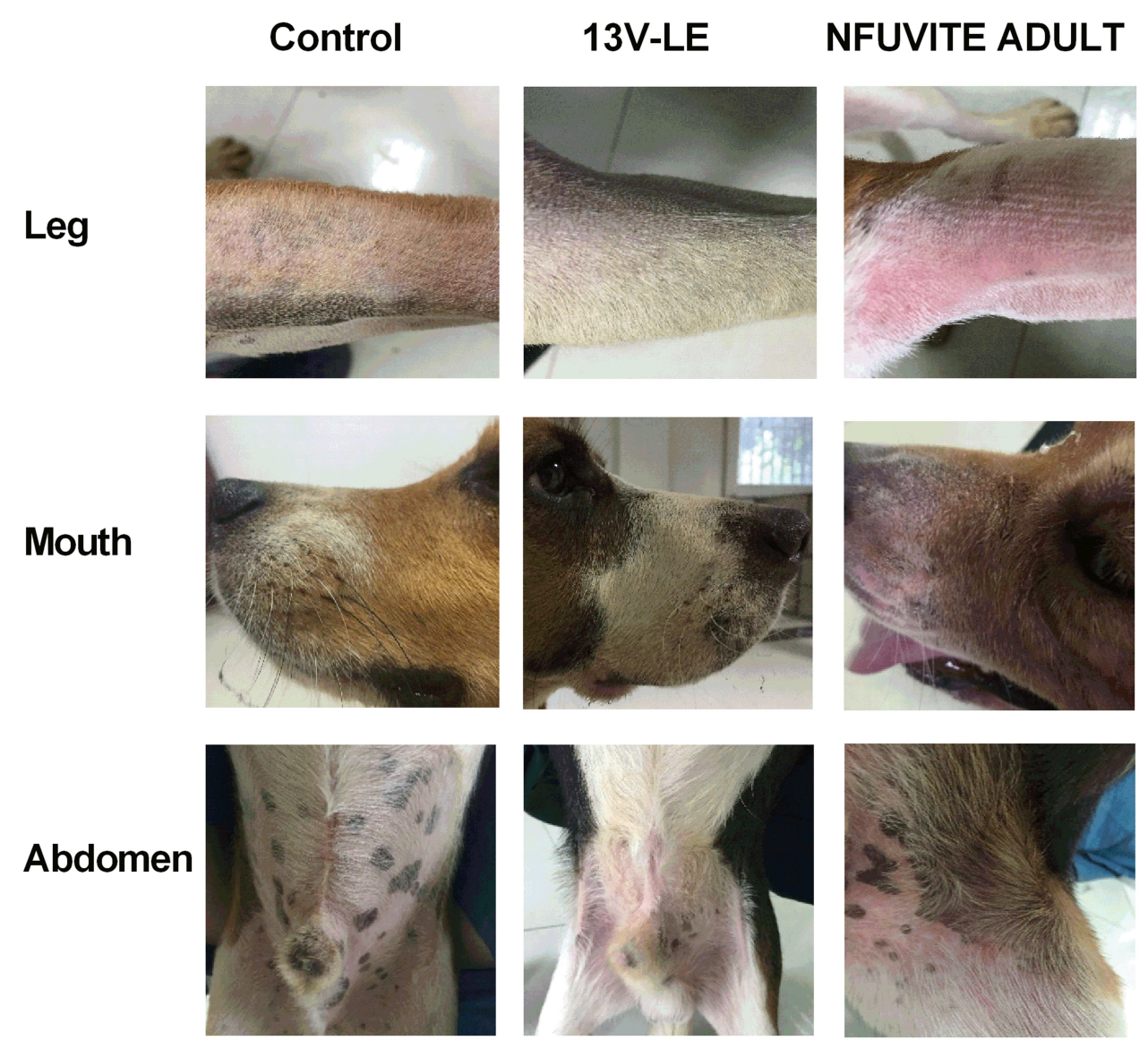

Figure 2 Skin manifestations on beagle dogs after intravenous administration of multiple vitamins. The photos were taken within 30 minutes after the administration, and are representative of six dogs.

administration ( $P>0.05$, Table 8). This demonstrated that 13V-LE did not increase plasma histamine, but Infuvite Adult induced an increase in plasma histamine, which is involved in the inflammatory response and itching.

Anaphylactoid reaction, also referred to pseudoallergy or nonallergic drug hypersensitivity, has clinical manifestations that are indistinguishable from anaphylaxis. ${ }^{34}$ Behavioris considered an important visual and intuitive method to determine anaphylactoid reactions. Beagle dogs are more sensitive and anaphylactoid reactions in them more easily observable than in mice and guinea pigs. ${ }^{35}$ This is the reason that Beagle dogs were used to investigate anaphylactoid reactions to $13 \mathrm{~V}$-LE. From the perspective of animal ethics, we try to minimize the number of animals. Therefore, we reused the dogs on the premise that the accuracy of the results would not be affected. From a pharmacokinetic perspective, $97 \%$ of a medicine can be eliminated after five elimination halflives. In fact, multivitamins cannot be sufficiently cleared from the body after 48 hours, because some vitamins have a long half-life. For example, vitamins $\mathrm{C}, \mathrm{D}_{3}$, E have halflives of approximately 10,15 , and $70-90$ hours, respectively. ${ }^{36,37}$ However, this had no influence on the anaphylactoid reaction results in this study. Firstly, anaphylactoid reaction is an immediate and transient reaction, and symptoms last for only a few hours. Anaphylactoid reaction is characterized by immediate and transient degranulation of mast cells. Clinical manifestations usually occur within 15 minutes of parenteral injection of the causative agent, reach the maximum usually within 60 minutes, and usually disappear after a few hours. ${ }^{38,39}$ Anaphylactoid reactions to Infuvite Adult disappeared after about 30 minutes. Secondly, the anaphylactoid reactions to Infuvite Adult were induced by Tween 80 , but not by the various vitamins. The plasma concentration of Tween 80 was $<0.05 \%$ (v:v) within 15 minutes after drug administration. ${ }^{40}$ From a pharmacokinetic perspective, Tween 80 can be sufficiently cleared in the body after 48 hours. Thirdly, in the same group, the results of behavioral observation and plasma histamine concentration on 

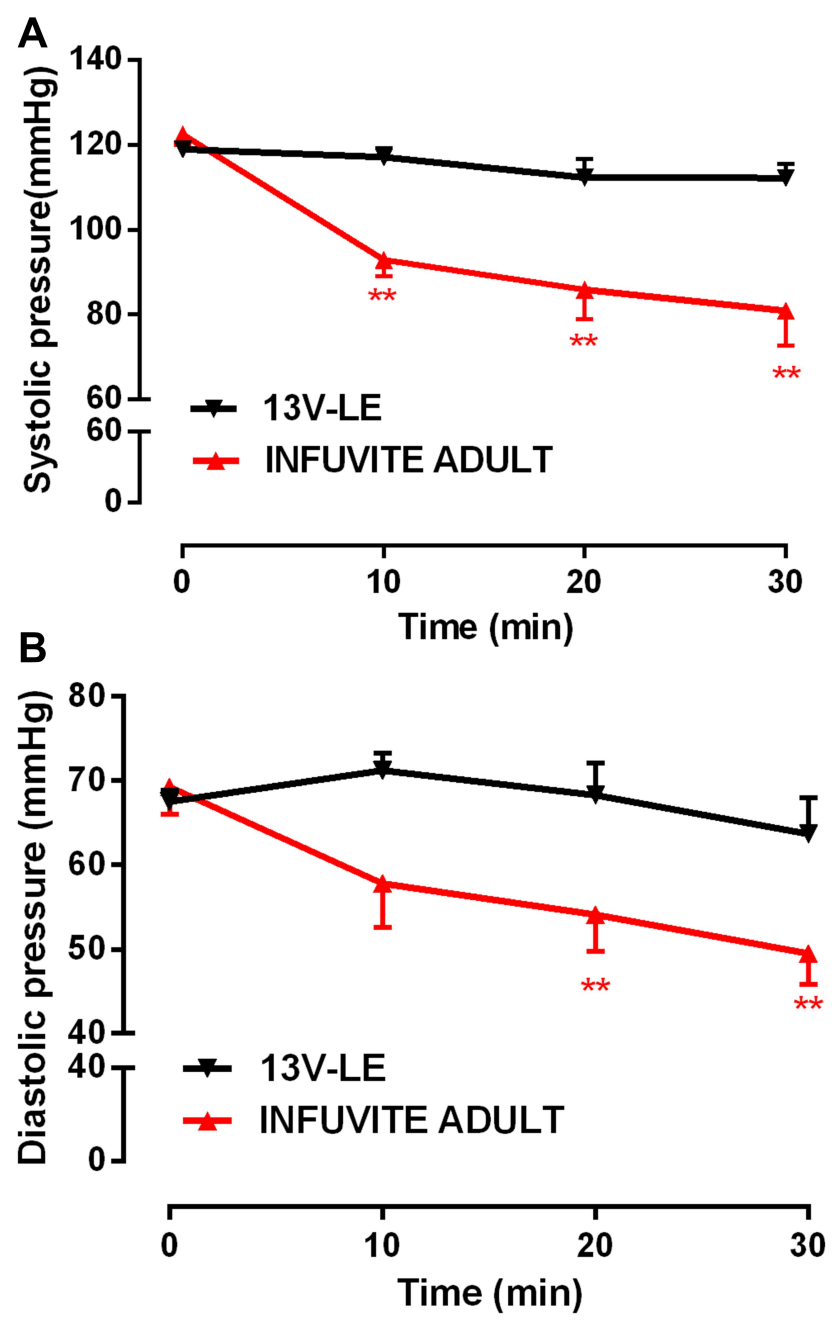

Figure 3 Effect of compound vitamins on blood pressure in beagle dogs. (A) Systolic pressure; (B) diastolic pressure. Means $\pm S E, n=6$. $* * P<0.01$ vs before administration.

the second day were consistent with the results on the fourth day. Therefore, reuse of dogs after 48 hours had no influence on the anaphylactoid reaction test.

Manifestations of anaphylaxis and anaphylactoid reactions are continuous. Weak cutaneous signs, such as rhinorrhea, flushing, and pruritus, often occur at the start. ${ }^{41}$ These symptoms in dogs are scratching the nose or head, flinging the ears, sneezing, coughing, skin or mucous

Table 8 Effect of multivitamins on plasma histamine

\begin{tabular}{|l|c|c|}
\hline & \multicolumn{2}{|c|}{ Histamine concentration $(\mu \mathrm{g} / \mathrm{mL})$} \\
\hline & Before administration & After administration \\
\hline I3V-LE & $2.5 \pm 0.2$ & $3.7 \pm 0.4$ \\
Infuvite Adult & $3.1 \pm 0.5$ & $5.7 \pm 0.9^{*}$ \\
\hline
\end{tabular}

Note: $* P<0.05$ vs before administration. rubeosis, and sialism. The manifestations further aggravate with gastrointestinal symptoms, such as nausea, vomiting, and diarrhea. ${ }^{41}$ In more serious cases, hypotension, laryngeal obstruction, severe bronchospasm, shock, and asphyxiation occur. ${ }^{41}$ Anaphylactoid reaction is related to the activation of mast cells via non-IgE-mediated degranulation. ${ }^{34}$ Mast cells can immediately respond to stimulants by degranulation releasing granule-associated mediators, such as histamine, lysosomes, and TNF, into the extracellular milieu, inducing immediate allergic reactions. ${ }^{42}$ Increases in plasma- or tissue-histamine levels have been noted during anaphylaxis and anaphylactoid reactions. ${ }^{41}$ Infuvite Adult containing Tween 80 induced anaphylactoid reactions, with serious symptoms (such as pruritus, skin rash, tachypnea, instability of gait, diarrhea, somnolence, hypodynamia, and wheezing), hypotension and high plasma-histamine levels. These reactions were similar to vitamin $K_{1}$ injections, with both containing Tween $80 .{ }^{17}$ However, behavior, blood pressure, and plasma histamine did not show obvious change in the dogs following administration of 13V-LE, suggesting that it did not induce anaphylactoid reactions.

\section{Conclusion}

$13 \mathrm{~V}-\mathrm{LE}$ is a novel multivitamin. In this formulation, fatsoluble vitamins and soybean oil were considered as oil phase, egg lecithin was chosen as an emulsifying agent, and water-soluble vitamins, glycerin, and water were considered as water phase. The formulation of 13V-LE displayed high EE with stable $\zeta$-potential, uniform distribution, and small particles, suitable for parenteral administration. Moreover, 13V-LE did not induce anaphylactoid reactions. This formulation of $13 \mathrm{~V}$-LE has promise as a new approach to avert hypersensitivity to multivitamins, and to simultaneously improve the stability of vitamins and dissolve water-soluble vitamins and fat-soluble vitamins.

\section{Acknowledgments}

This study was supported by grants from the National Natural Science Foundation of China (81803647), China Postdoctoral Science Foundation (2017M613155), and Shaanxi Province Postdoctoral Science Foundation (2018BSHEDZZ94). We would like to thank Jing Liu and Pingping Yan at the Department of Pharmacology, Xi'an Jiaotong University College of Medicine for their kind help and support with the experiments. 


\section{Disclosure}

The authors report no conflicts of interest.

\section{References}

1. Coleman J, Pontefract SK. Adverse drug reactions. Clin Med (Northfield Il). 2016;16(5):481-485. doi:10.7861/clinmedicine.165-481

2. Bouvy JC, De Bruin ML, Koopmanschap MA. Epidemiology of adverse drug reactions in Europe: a review of recent observational studies. Drug Saf. 2015;38(5):437-453. doi:10.1007/s40264-0150281-0

3. Lisha J, Annalakshmi V, Maria J, Padmini D. Adverse drug reactions in critical care settings: a systematic review. Curr Drug Saf. 2017;12 (3):147-161. doi:10.2174/1574886312666170710192409

4. Bohm R, Cascorbi I. Pharmacogenetics and predictive testing of drug hypersensitivity reactions. Front Pharmacol. 2016;7:396. doi:10.3389/fphar.2016.00396

5. Niedert KC. Position of the American Dietetic Association: liberalization of the diet prescription improves quality of life for older adults in long-term care. J Am Diet Assoc. 2005;105(12):1955-1965.

6. Bharadwaj S, Ginoya S, Tandon P, et al. Malnutrition: laboratory markers vs nutritional assessment. Gastroenterol Rep. 2016;4 (4):272-280. doi:10.1093/gastro/gow013

7. Malone A, Hamilton C. The Academy of Nutrition and Dietetics/the American Society for Parenteral and Enteral Nutrition consensus malnutrition characteristics: application in practice. Nutr Clin Pract. 2013;28(6):639-650. doi:10.1177/0884533613508435

8. Mulasi U, Kuchnia AJ, Cole AJ, Earthman CP. Bioimpedance at the bedside: current applications, limitations, and opportunities. Nutr Clin Pract. 2015;30(2):180-193. doi:10.1177/0884533614568155

9. Benoist S, Brouquet A. Nutritional assessment and screening for malnutrition. J Visc Surg. 2015;152(Suppl 1):S3-S7. doi:10.1016/ s1878-7886(15)30003-5

10. Hu W-H, Cajas-Monson LC, Eisenstein S, Parry L, Cosman B, Ramamoorthy S. Preoperative malnutrition assessments as predictors of postoperative mortality and morbidity in colorectal cancer: an analysis of ACS-NSQIP. Nutr J. 2015;14. doi:10.1186/s12937-0150081-5

11. Mahgoub HM, Adam I. Morbidity and mortality of severe malnutrition among Sudanese children in New Haifa Hospital, Eastern Sudan. Trans $R$ Soc Trop Med Hyg. 2012;106(1):66-68. doi:10.1016/j. trstmh.2011.09.003

12. Martin AN, Das D, Turrentine FE, Bauer TW, Adams RB, Zaydfudim VM. Morbidity and mortality after gastrectomy: identification of modifiable risk factors. J Gastrointestinal Surg. 2016;20 (9):1554-1564. doi:10.1007/s11605-016-3195-y

13. Munthali T, Jacobs C, Sitali L, Dambe R, Michelo C. Mortality and morbidity patterns in under-five children with severe acute malnutrition (SAM) in Zambia: a five-year retrospective review of hospitalbased records (2009-2013). Arch Public Health. 2015;73. doi:10.1186/s13690-015-0072-1

14. Caccialanza R, Cereda E, Klersy C. Malnutrition, age and inhospital mortality. CMAJ. 2011;183(7):826. doi:10.1503/cmaj.111-2038

15. Macpherson H, Pipingas A, Pase MP. Multivitamin-multimineral supplementation and mortality: a meta-analysis of randomized controlled trials. Am J Clin Nutr. 2013;97(2):437-444. doi:10.3945/ ajcn.112.049304

16. American Medical Association.Multivitamin preparations for parenteral use - statement by the nutrition advisory group. $J$ Parenteral Enteral Nutr. 1979;3(4):258-262. doi:10.1177/014860717900300410

17. Mi YN, Ping NN, Xiao X, Zhu YB, Liu J, Cao YX. The severe adverse reaction to vitamin $\mathrm{k} 1$ injection is anaphylactoid reaction but not anaphylaxis. PLoS One. 2014;9(3):e90199. doi:10.1371/journal. pone. 0090199
18. Sun WW, Li YK, Zhang JY. [Anaphylactoid reactions inducing effect of polysorbate 80 and polysorbate 80 contained Houttuynia cordata injection on beagle]. Zhongguo Zhong Xi Yi Jie He Za Zhi. 2011;31 (1):90-93. Chinese.

19. Coors EA, Seybold H, Merk HF, Mahler V. Polysorbate 80 in medical products and nonimmunologic anaphylactoid reactions. Ann Allergy Asthma Immunol. 2005;95(6):593-599. doi:10.1016/S1081-1206(10) 61024-1

20. Hernandez CR, Ponce EC, Busquets FB, et al. Hypersensitivity reaction to components of parenteral nutrition in pediatrics. Nutrition. 2016;32(11-12):1303-1305. doi:10.1016/j.nut.2016.04.010

21. Bartels CL, Sanz C, Stec R, Coulter DW. Parenteral nutrition-induced hypersensitivity in an adolescent. JPEN $J$ Parenter Enteral Nutr. 2012;36(1):117-121. doi:10.1177/0148607111399288

22. Orfan NA, Dykewicz MS, Rosand J, Bertino J. anaphylaxis induced by folate in a multivitamin. J Allergy Clin Immunol. 1995;95(1):371.

23. Christian VJ, Tallar M, Walia CLS, Sieracki R, Goday PS. Systematic review of hypersensitivity to parenteral nutrition. $J$ Parenteral Enteral Nutr. 2018;42(8):1222-1229. doi:10.1002/jpen.1169

24. Fell GL, Nandivada P, Gura KM, Puder M. Intravenous lipid emulsions in parenteral nutrition. Adv Nutr. 2015;6(5):600-610. doi:10.3945/an.115.009084

25. Zhang X, Wu B. Submicron lipid emulsions: a versatile platform for drug delivery. Curr Drug Metab. 2015;16(3):211-220. doi:10.2174/ 138920021603150812124221

26. Tayeb HH, Sainsbury F. Nanoemulsions in drug delivery: formulation to medical application. Nanomedicine. 2018;13(19):2507-2525. doi:10.2217/nnm-2018-0088

27. Health N. National Institutes of Health State-of-the-Science Conference Statement: multivitamin/mineral supplements and chronic disease prevention. Am J Clin Nutr. 2007;85:257S-264S.

28. O S, W A. Intravenous infusion of fat emulsions, phosphatides and emulsifying agents. Acta Chir Scand Suppl. 1961;278(1-12).

29. van Hoogevest P, Wendel A. The use of natural and synthetic phospholipids as pharmaceutical excipients. Eur J Lipid Sci Technol. 2014;116(9):1088-1107. doi:10.1002/ejlt.201400219

30. Sk L, Aa K. Preharvest and postharvest factors influencing vitamin C content of horticultural crops. Postharvest Biol Technol. 2000;20:207-220. doi:10.1016/S0925-5214(00)00133-2

31. M V, S J, K D, M V, Gk R. Effects of various dehydration methods and storage on physicochemical properties of guava powder. $J$ Food Sci Technol. 1993. doi:10.1007/s13197-013-1020-0

32. Rahman MS, Al-Rizeiqi MH, Guizani N, Al-Ruzaiqi MS, Al-Aamri $\mathrm{AH}$, Zainab S. Stability of vitamin $\mathrm{C}$ in fresh and freeze-dried capsicum stored at different temperatures. J Food Sci Technol. 2015;52(3):1691-1697. doi:10.1007/s13197-013-1173-x

33. Folino TB, Muco E, Safadi AO, Parks LJ. Propofol, in StatPearls. Treasure Island (FL); 2020.

34. Farnam K, Chang C, Teuber S, Gershwin ME. Nonallergic drug hypersensitivity reactions. Int Arch Allergy Immunol. 2012;159 (4):327-345. doi:10.1159/000339690

35. Mi YN, Ping NN, Xiao X, Wang C, Zhu YJ, Cao YX. A sensitive beagle dog model to evaluate anaphylactoid reactions. Allergologie. 2015;38(10):491-497. doi:10.5414/ALX011794

36. Jones G. Pharmacokinetics of vitamin D toxicity. Am J Clin Nutr. 2008;88(2):582S-586S. doi:10.1093/ajen/88.2.582S

37. Schwedhelm E, Maas R, Troost R, Boger RH. Clinical pharmacokinetics of antioxidants and their impact on systemic oxidative stress. Clin Pharmacokinet. 2003;42(5):437-459. doi:10.2165/00003088200342050-00003

38. Levy JH, Roizen MF, Morris JM. Anaphylactic and anaphylactoid reactions. A review. Spine. 1986;11(3):282-291. doi:10.1097/ 00007632-198604000-00017

39. Ring J, Behrendt H. Anaphylaxis and anaphylactoid reactions. Classification and pathophysiology. Clin Rev Allergy Immunol. 1999;17(4):387-399. doi:10.1007/BF02737644 
40. van Tellingen O, Beijnen JH, Verweij J, Scherrenburg EJ, Nooijen WJ, Sparreboom A. Rapid esterase-sensitive breakdown of polysorbate 80 and its impact on the plasma pharmacokinetics of docetaxel and metabolites in mice. Clin Cancer Res. 1999;5 (10):2918-2924.
41. Rusznak C, Peebles RS Jr. Anaphylaxis and anaphylactoid reactions. A guide to prevention, recognition, and emergent treatment. Postgrad Med. 2002;111(5):101-104. doi:10.3810/pgm.2002.05.1207

42. Wernersson S, Pejler G. Mast cell secretory granules: armed for battle. Nat Rev Immunol. 2014;14(7):478-494. doi:10.1038/nri3690

\section{Publish your work in this journal}

The International Journal of Nanomedicine is an international, peerreviewed journal focusing on the application of nanotechnology in diagnostics, therapeutics, and drug delivery systems throughout the biomedical field. This journal is indexed on PubMed Central, MedLine, CAS, SciSearch ${ }^{\circledR}$, Current Contents ${ }^{\circledR} /$ Clinical Medicine, $^{\circ}$
Journal Citation Reports/Science Edition, EMBase, Scopus and the Elsevier Bibliographic databases. The manuscript management system is completely online and includes a very quick and fair peer-review system, which is all easy to use. Visit http://www.dovepress.com/ testimonials.php to read real quotes from published authors. 